\title{
Compaction Characteristics of BC Soil Reinforced with Untreated and Treated Coir Fibers
}

\author{
Rajnish Kumar ${ }^{*}$, Saurabh Singh ${ }^{2}$, S S Divya ${ }^{3}$,Shahanawaz Ahmed Mir $^{4}$ \\ ${ }^{1}$ Master's Student, Suresh Gyan Vihar University, Jaipur, India. \\ ${ }^{2,3,4}$ Assistant Professor, Suresh Gyan Vihar University, Jaipur, India
}

\begin{abstract}
Black cotton soils, because of its high swelling and shrinkage characteristics has been a challenge to geotechnical engineers. Use of natural materials such as jute, cotton, coir, etc. as reinforcing materials in soil has the advantage that they are locally available with practically no cost. Out of all the natural fibers, coir has the greatest tearing strength and retains this property even in wet conditions. It has been used in noncritical civil engineering applications. In this context, compaction characteristics of black cotton soil (BC Soil) admixed at different percentage of untreated and treated coir fibers were used with optimum lime content and without lime content. The present study indicated that the maximum dry density decreases with increasing percentage of coir fibers for both BC soil with and without optimum lime. Marginal variation in MDD when fiber content is varied from 0 to $0.5 \%$ occurs and beyond $0.5 \%$ fiber content (FC) significant reduction in MDD occurs. Increasing FC increases the corresponding OMC indicating addition of fiber increases water absorption by coir fibers causing an increase in OMC. However the alkali treatment of coir fiber causes a significant reduction in water absorption-leading to significant improvement in compaction characteristics of $\mathrm{BC}$ soil
\end{abstract}

Keywords: Compaction, Black cotton soil, Alkali treatment, Coir Fiber, maximum dry density

\section{INTRODUCTION}

Black cotton (BC) soil in India is expansive nature, which cover more than one-fifth of the country and spread over the states like Maharashtra, north part of Karnataka, Gujarat, and southern part of Utter Pradesh, eastern part of Rajasthan, southern and western part of Madhya Pradesh, and few parts of Andhra Pradesh. Construction of engineering structures on $\mathrm{BC}$ soil is problematic and highly risky because, such soil causes differential settlements due to its poor shear strength and high compressibility[26, 27, 28, 30]. The strength improvement can be undertaken by a variety of ground improvement techniques including the use of reinforcement techniques and [1 and 2]. Chemical stabilization like cement or lime also has proved to be the best technique for improving the performance of soil [3, 4, 5, 6 and 7]. The main advantages of using reinforcement in the form of short fibers to improve properties of BC soil to the desired extent are: absence of potential plane of weakness, feasibility of application within a limited space compared and significant cost savings because of the availability of fibers at lower cost and no need for a specific design. Among natural fibers, fibers obtained from coir in proven to be most durable when used in soils because of it having high lignin content. Hence the use of coir fibers in black cotton soil is examined in this context. However, a major drawback associated with natural coir fibers is high water absorption of the fibers, causing the deterioration of its strength in a short span of time. It is necessary to impart hydrophobicity to natural fibers with suitable surface treatment $[8,9,10$ and 11$]$, to increase the long lasting qualities of fibers when introduced in soils. Surface modification of fiber does not only decrease moisture adsorption but also improve the interfacial bond strength. Used effectively, the rural economy can get uplift; the cost of construction can be reduced, if the material use leads to beneficial effects in engineering construction. Several studies have been conducted by various investigators regarding the effectiveness of surface treatment of natural fibers. Several chemical methods such as alkali treatment, acetylated treatment, permagnate treatment, heat treatment have been tried. Alkaline treatment is one among the best used as it promotes the removal of partially amorphous constituents and therefore reduces the level of fiber aggregation and makes rougher surface [12,13 and 14] Adhesion can be improved by surface modification of coir fiber. Further, treated coir fiber showed better impact strength [15 and 16]. The objective of the present investigations is thus to ssurface modify coir fibre to make it water repellent and to study and compare compaction characteristics of untreated and treated coir fibre reinforced BC soil. The effect of lime addition on compaction characteristics of coir fiber reinforced soil has also been verified-as lime is one of the popular stabilizing agent most commonly used.

\section{MATERIALS AND METHODS}

\section{Black Cotton Soil and Lime}

Black cotton soil (BC soil) was collected from Sriganganagar, Kota, Rajasthan India by an open excavation at a depth of $1.5 \mathrm{~m}$ below the ground level. Black cotton soil was air dried and pulverized in a ball mill after separating the pebbles. The pulverized soil, which is passing through 425-micron BIS sieve, was used in the present investigation. The basic properties of soil such as grain size, specific gravity, and Atterberg limits were determined. The soil can be classified as inorganic clay with high plasticity $(\mathrm{CH})$, with physical properties of the $\mathrm{BC}$ soil being as shown in Table 1 and particle size distribution of BC soil used is as shown in Figure1. Lime supplied by Durga lime Industries, Daijar, Rajasthan has been used for experimental purpose 
Table 1. Properties of black cotton soil

\begin{tabular}{|c|c|}
\hline Properties & Values \\
\hline Liquid Limit, LL (\%) & 67 \\
\hline Plastic Limit, PL (\%) & 22 \\
\hline Shrinkage Limit, SL (\%) & 11 \\
\hline Specific gravity, G & 2.66 \\
\hline Percentage of Fine Sand & 21 \\
\hline Percentage of Silt & 20.2 \\
\hline Percentage of Clay & 58.8 \\
\hline
\end{tabular}

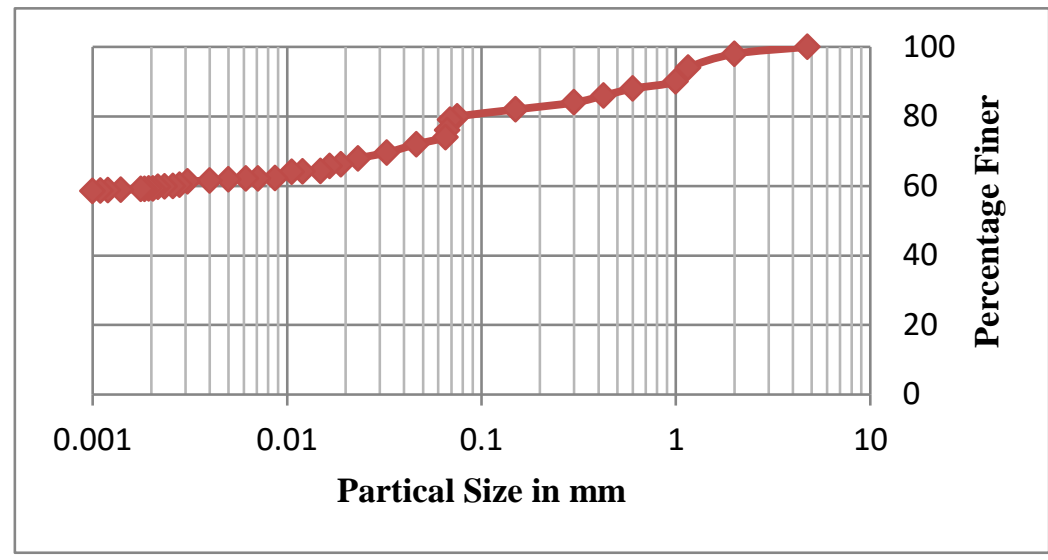

Fig 1 Sieve analysis of BC Soil

\section{COIR FIBERS}

Coir fibers cut into various average length of 10-20 mm was used as a natural reinforcing material. The average length of 10-20 mm was decided based on strength test under triaxial conditions on samples of BC soil mixed with coir fibers of varied length and percentage that gave maximum strength. The same length of the coir fibers were implemented to determine compaction characteristics to $\mathrm{BC}$ soil that gave maximum strength. The results of the effect of aspect ratio have been published elsewhere [17]. Coir fibers used were brownish in color and was obtained from the local small scale factory in Chandra Prakash \& Company, Jaipur, Rajasthan, India. Table 2 shows chemical composition and mechanical properties of coir fiber used.

Table2 Chemical composition of coir fiber

(Courtesy: Civil-Aid Techno-clinic Private Limited, Bengaluru)

\begin{tabular}{|c|c|}
\hline Properties & Percentage \\
\hline Total water soluble & 6.00 \\
\hline Hemi-celluloses & 11.08 \\
\hline Lignin & 49.23 \\
\hline Cellulose & 26.29 \\
\hline \multicolumn{2}{|c|}{ Mechanical Properties } \\
\hline Properties & Value \\
\hline Tensile strength in MPa & 90 \\
\hline Thickness in mm & 0.45 \\
\hline Elongation \% & $15-17.3$ \\
\hline
\end{tabular}

\section{SURFACE TREATMENT OF COIR FIBERS}

On the basis of review of literatures[18,19,20 and 21], alkali treatment was adopted to surface modify the coir fibers to be used as reinforcement in $\mathrm{BC}$ soil and the compaction characteristics of the same were compared with untreated coir fiber reinforced BC soil. Surface modifications of coir fiber were carried out in stages as follows: (i) the coir fibers were scoured with hot detergent solution of $2 \%$ concentration at a temperature of $70^{\circ} \mathrm{C}$ for about 1 hour. After completion of this process the fibers were washed with distilled water and finally air dried. (ii) The fibers were then immersed in a mixture of 1:2 Ethanol and Benzene for a period of 720 hours to dewax the fibers. These fibers were then washed with distilled water and then air dried. (iii)
Dewaxed fibers were alkali treated with $\mathrm{NaOH}$ solution of $6 \%$ concentration at a temperature of $100^{\circ} \mathrm{C}$ for a period of 3hours. After the completion of this process the fibers were washed several times to remove the absorbed alkali. Later they were air dried for a period of 48 hours, to obtain alkali treated fibers (iv) Finally, alkali treated fibers were coated with water based epoxy resin (available in the brand name DAMPGUARD 104, commonly known as Dr. Fixit, whose properties as shown in Table 3) The resin was mixed in the ratio 1:1:2 (hardener: base: water) and simultaneously sprinkled with stone dust passing75 micron BIS sieve. Before using the treated coir fiber as admixture in BC Soil it was air-dried for a period 48 hours. 
Table3 Technical Information of Dr.FIXIT DAMPGUARD 104

\begin{tabular}{|c|c|c|}
\hline Properties & Specification & Results \\
\hline Nature & & Two component \\
\hline Mixing ratio, by weight (Base: Hardener: Water & & $1: 1: 2$ \\
\hline Consistency & & Free flowing smooth paste \\
\hline Pot life at 30 $\mathrm{C}$, Minutes & & 40 Minimum \\
\hline Surface drying time at $30^{\circ} \mathrm{C}$, hrs & & $5-6$ \\
\hline Inter-coat periods, at $30^{\circ} \mathrm{C}, \mathrm{hrs}$ & $6-8$ \\
\hline Water absorption at $38^{\circ} \mathrm{C}$ & ASTM C 870: 90 & Nil \\
\hline Adhesion strength, N/mm & ASTM D 4541:02 & 2.5 (Failure occurred in the system) \\
\hline
\end{tabular}

\section{WATER ABSORPTION CHARACTERISTICS OF SURFACE TREATED COIR FIBERS}

Water absorption of untreated, alkali treated and alkali treated with water based epoxy resin coated samples of coir fibers were determined by immersing all the three in water up to 90 days. Initially dry weight of the fiber is taken, then the wet weight of coir fibers at the end of each curing period was noted and finally these fibers were dried in oven for 6 hours at $60^{\circ} \mathrm{C}$ and the weight was noted down. The water absorption of coir fibers was determined in percentage as the ratio of weight of water to the weight of dry fibers $[22,23$ and 24]. Fig 2 shows variation of percentage water absorption with age in days for all the fibers tested in lab. It can be seen that untreated coir fibers indicated high water absorption at around $90 \%$. Trends obtained for alkali treated coir fibers and alkali treated with water based epoxy resin coated fibers exhibited significant reduction in water absorption at all curing period in days. It is evident that alkali treated and coated with water based epoxy resin exhibits better reduction in water absorption when compared to alkali treated fibers.

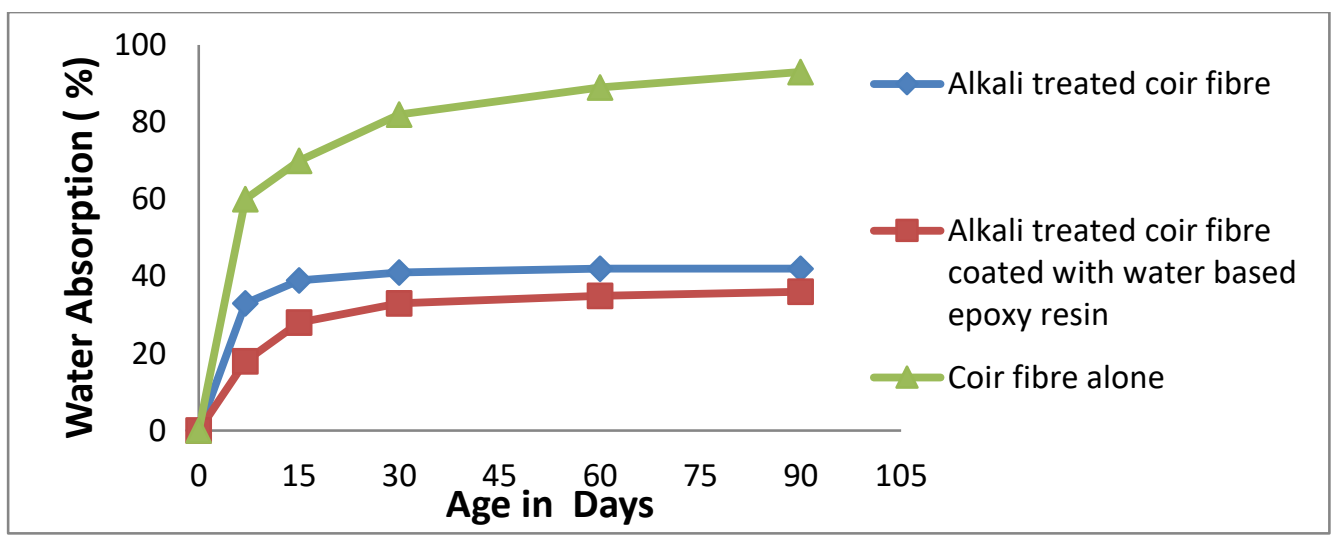

Fig 2 Water absorption of Untreated and Surface Treated Coir Fiber

\section{COMPACTION CHARACTERISTICS OF UNTREATED AND TREATED COIR FIBERS}

\section{Determination of Optimum Lime Content}

In order to study the performance of coir fibers in lime treated BC soil, tests were conducted on black cotton soil with increasing percentage of lime to determine the optimum lime for the $\mathrm{BC}$ soil to be used for coir fiber reinforcement. Compaction test was conducted using provisions for light compaction test as per the BIS standards IS: 2720 (Part VII-1980). Fig 5 shows typical compactions curves obtained for BC soil treated with different percent of lime. Using the results of dry density- moisture content of lime treated BC soil, the optimum lime content was determined.

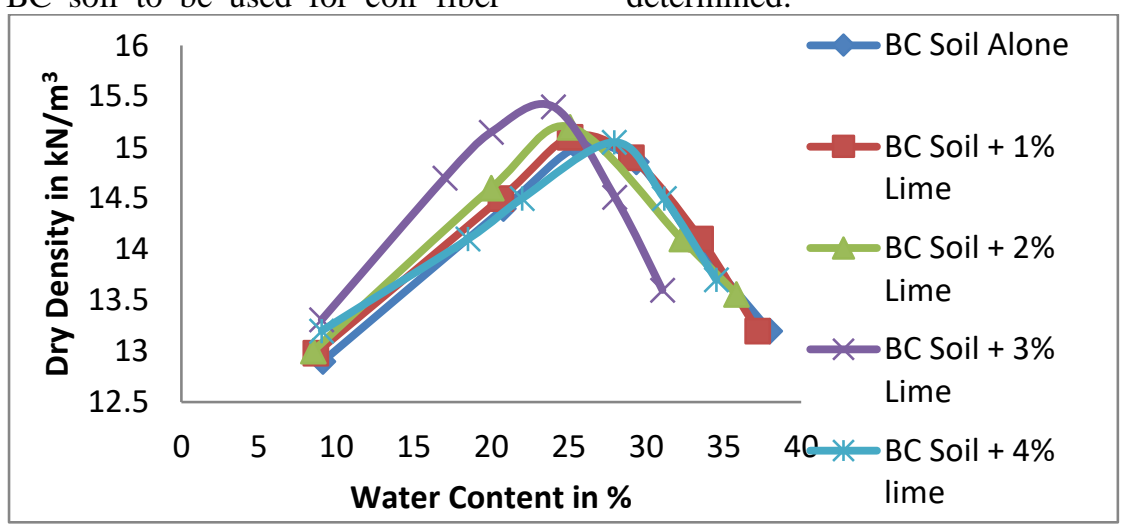

Fig 5 Compaction Curves for BC Soil with Different Percentages of Lime. 
Table 4 shows variation of MDD and OMC at different percentage of lime added to BC soil. It can be seen that, corresponding to $3 \%$ lime content, MDD is maximum with minimum $\mathrm{OMC}$ for the $\mathrm{BC}$ soil used in the present investigation. Hence, for the $\mathrm{BC}$ soil used in the experimental investigation, $3 \%$ lime can be considered as optimum lime content (OLC). Effect of untreated and surface treated coir fiber were determined by adding coir fibers at different percentages to BC soil treated with $3 \%$ OLC to determine effect of randomly distributed fibers (RDF) on lime treated BC soil,

Table 4 Variation of MDD and OMC with Lime Content

\begin{tabular}{|c|c|c|}
\hline $\begin{array}{c}\text { Lime(L) } \\
\mathbf{\%}\end{array}$ & $\begin{array}{c}\text { MDD } \\
\mathbf{k N} / \mathbf{m}^{3}\end{array}$ & $\begin{array}{c}\text { OMC } \\
(\mathbf{\%})\end{array}$ \\
\hline $1 \% \mathrm{~L}+\mathrm{BC}$ & 15.1 & 25.085 \\
\hline $2 \% \mathrm{~L}+\mathrm{BC}$ & 15.2 & 25.09 \\
\hline $3 \% \mathrm{~L}+\mathrm{BC}$ & 15.4 & 24.034 \\
\hline $4 \% \mathrm{~L}+\mathrm{BC}$ & 15.05 & 27.972 \\
\hline
\end{tabular}

Compaction characteristics of $\mathrm{BC}$ soil mixed with different percentage of coir fibers having average length of $10-20 \mathrm{~mm}$ were determined using procedure for light compaction. Untreated coir fibers (UCF), treated coir fibers (TCF) were used. The effect of presence of lime was also verified using optimum lime treated BC soil with UCF and TCF at different percentage.

\section{COMPACTION CHARACTERISTICS OF UNTREATED AND TREATED COIR FIBERS WITH AND WITHOUT OLC}

The dry density-moisture content of BC soil admixed with $\mathrm{UCF}$ were determined using procedure for light compaction, with average length of coir fiber used were between 10-20 $\mathrm{mm}$ as stated earlier. Fig 6 shows compaction curves thus obtained for BS soil reinforced with different percentage of untreated coir fibers (UCF). Similar compaction tests on BC soil admixed with different percentage of treated coir fiber (TCF) as well as gave BC soil with UCF and TCF along with optimum lime content are as shown in Fig 7, 8 and 9. From the results of these tests, the maximum dry density and optimum moisture content was obtained and the variation of MDD and OMC was plotted for different types of coir fiber admixed BC soil.
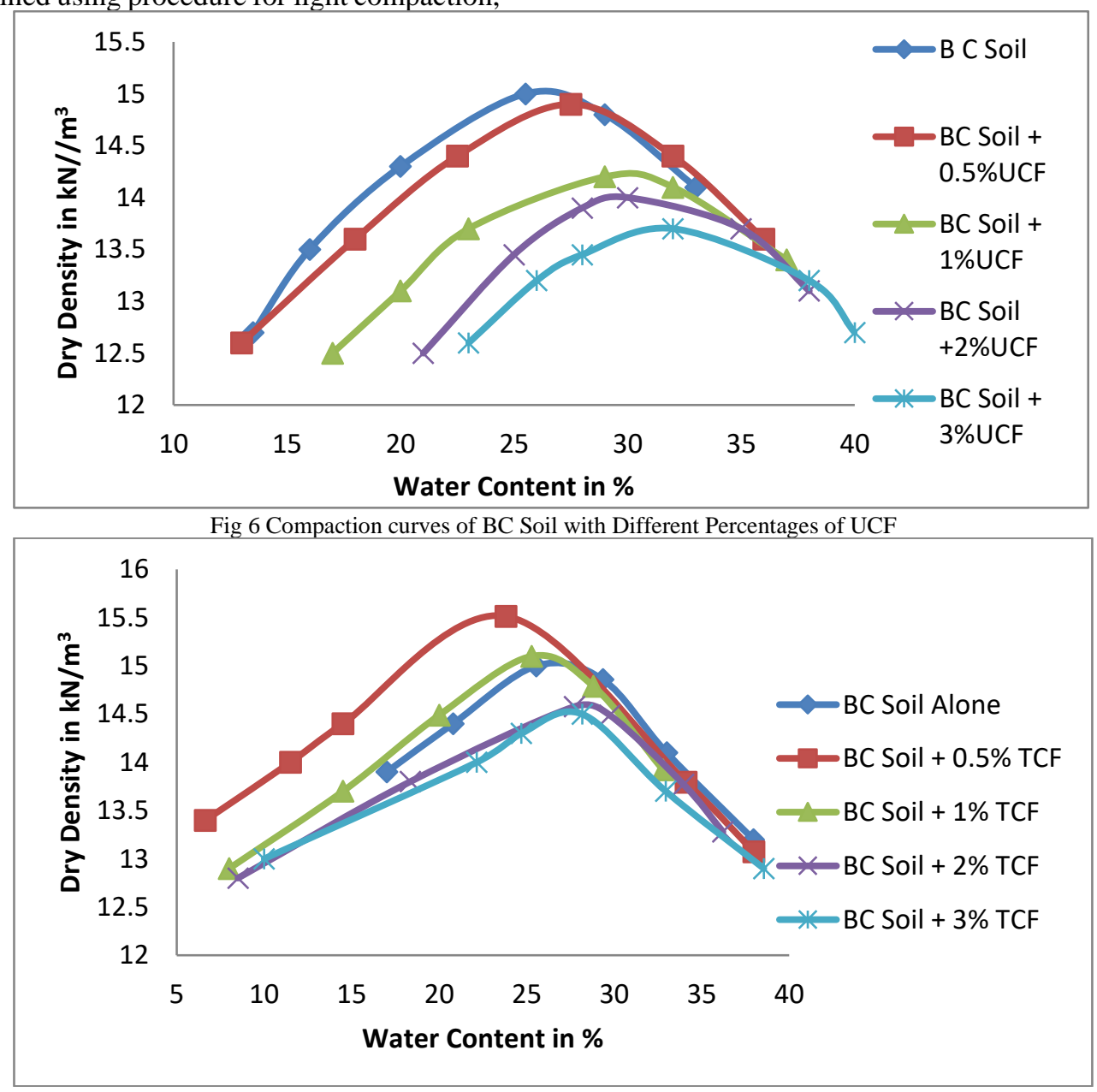

Fig 7 Compaction Curves of BC Soil with Different Percentages of TCF 


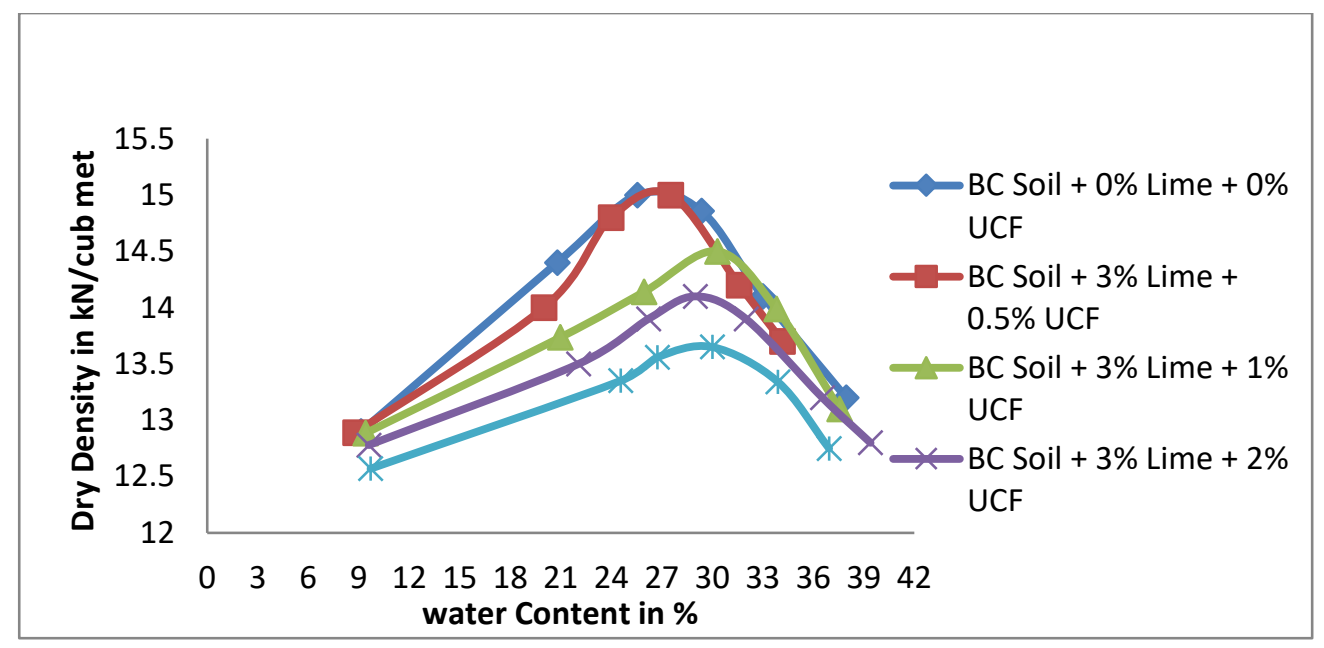

Fig 8 Compaction Curves of BC Soil with Different Percentages of UCF with Optimum Percent of lime

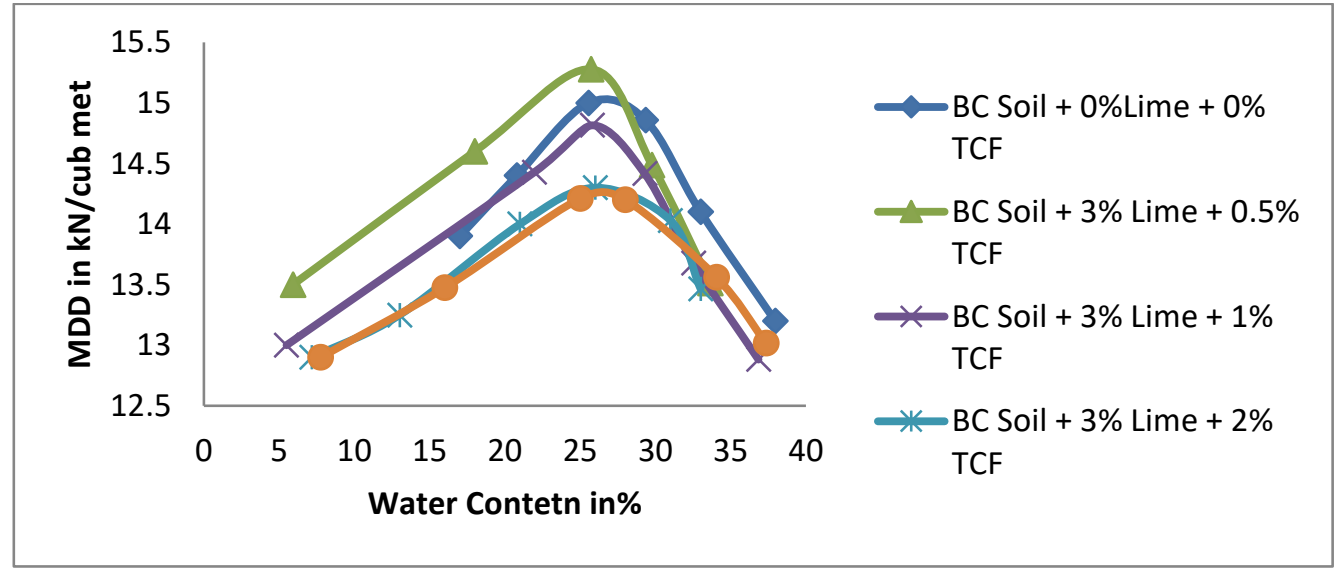

Fig 9 Compaction Curves of BC Soil with Different Percentages of TCF with Optimum Percent of lime

Fig. 10 shows the comparative variation of MDD with fiber content obtained for both UCF and TCF admixed BC soil with and without lime respectively. It can be seen that the MDD decreases with increasing percentage of untreated coir fibers for both BC soil with and without lime. This is attributed to the fact that increasing volume of low-density

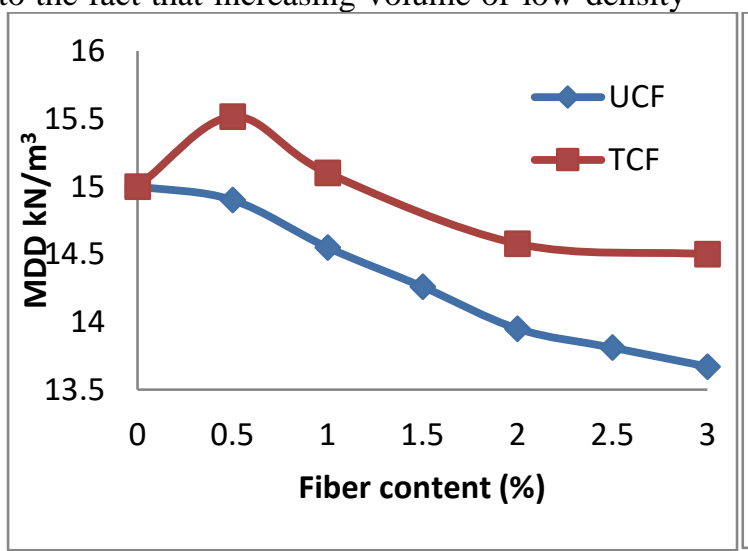

(a) BC Soil without Lime

Fig 10 MDD with Different \% of UCF and TCF for BC Soil with and without Lime Content coir fiber decreases the density of the compacted soil in addition to causing disintegration of soil particles with the addition of the coir, especially in lime treated BC soil[25]. However, it was observed that there is a marginal increase in MDD obtained for BC soil admixed with TCF.

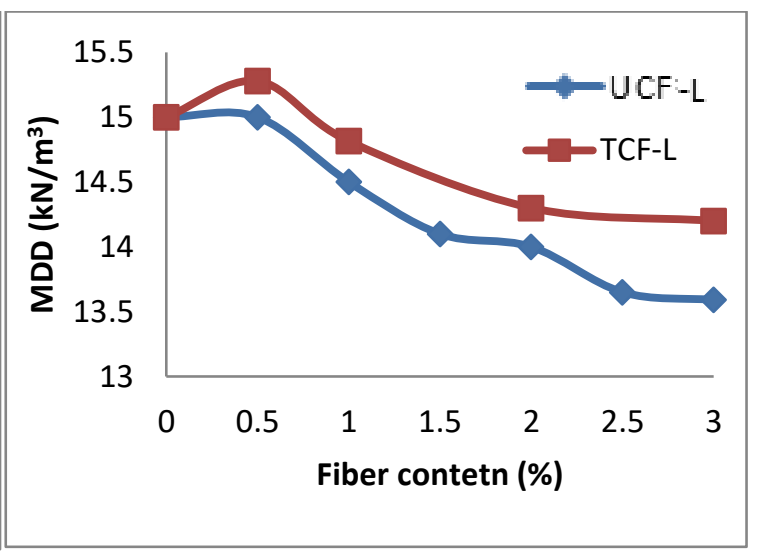

(b) BC Soil with Optimum Lime 
Fig 11 show the variation of OMC with fiber content obtained for both UCF and TCF admixed BC soil with and without lime respectively. It can be seen that OMC increases with increase in the fiber content with and without lime when UCF was admixed to BC soil. The reason for the trend can be attributed to the fact that water absorption of UCF increases with increase in fiber content, as UCF has greater water absorption leading to its volumetric expansion-that also seem to cause corresponding reduction in MDD. However, since the water absorption of TCF is significantly smaller as proved in water absorption tests, the corresponding OMC obtained when TCF was admixed is significantly smaller in comparison to UCF admixed BC soil with and without lime. Further, the OMC obtained for $0.5 \%$ TCF admixed BC soil is marginally smaller when compared to other percentage of TCF admixed BC soil.

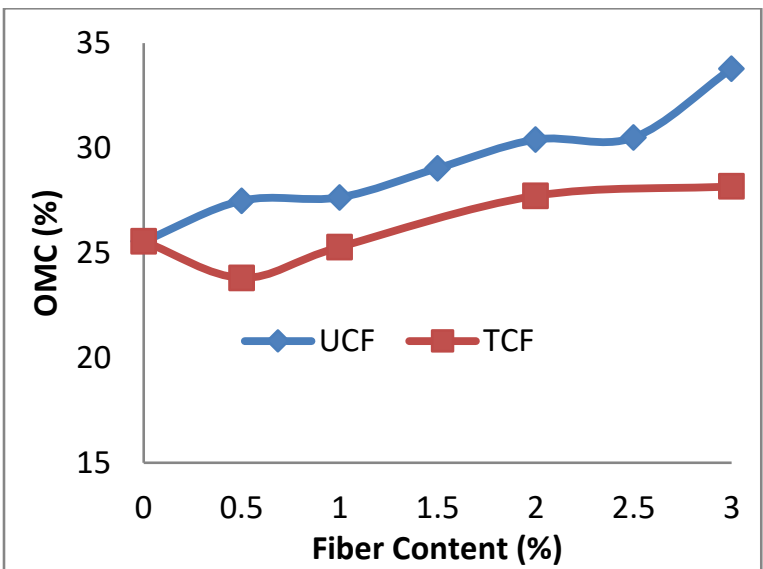

(a) BC Soil without Lime

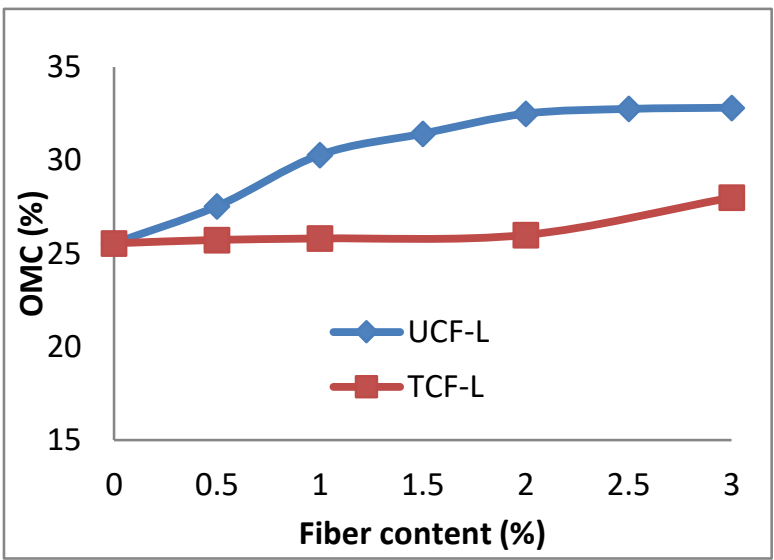

(b) BC Soil with Optimum Lime

Fig 11 OMC with Different \% of UCF and TCF for BC Soil with and without Lime Content

The study have indicated that the results of compaction test shows higher MDD \& lower OMC for BC soil admixed with treated coir fiber at $0.5 \%$, for the case of both BSC soil with and without lime.

\section{CONCLUSIONS}

Based on present experimental study, the following major conclusions have been drawn:

- Alkali treatment of coir fiber proposed in the study reduces the water absorption capacity of the coir fibers significantly making it longer lasting reinforcing material for $\mathrm{BC}$ soil.

- The effect of alkali treatment and epoxy based resin coating along with stone dust sprinkling increases surface roughness significantly-thereby development of better bond is possible when admixed with BC soil.

- Development of better bonding when TCF was admixed is clearly evident as per SEM study-thus altering compaction characteristics of $\mathrm{BC}$ soilleading to increase in MDD and corresponding reduction in OMC.

- Results of compaction tests have clearly indicated the beneficial effect of TCF is maximum when percentage of coir fiber is at around 0.5 .

- The decrease in OMC is attributed to reduction in water absorption capacity of TCF and increase in MDD is attributable to increase in surface roughness that leads to better bonding in $\mathrm{BC}$ soil.

- The veracity of reduction in water absorption of TCF may thus lead to increase in life span of coir fiber in retaining tensile strength for a longer duration when introduced in $\mathrm{BC}$ soil. The effect of curing in retaining strength of TCF for a longer duration need to be assessed.

- Treated coir fibers with long lasting strength in BC soil and with lower water absorption, and available abundantly in developing countries can be used extensively for stabilizing problematic soil for many infrastructure applications extensively, generating employment through the use of cheap and abundantly available natural fibers.

\section{REFERENCES}

[1] Maher M.H and Ho.Y.C. (1994). Mechanical properties of kaolinite/fiber soil composite. Journals of geotechnical engineering, Vol.120. No.8, P.No.4405.

[2] Cai, Y., Shi, B., Ng, C. W. W., and Tang, C. (2006). "Effect of polypropylene fiber and lime admixture on engineering properties of clayey soil.” J.Eng.Geo. 87(3-4), 230-240.

[3] Ramesh , H.N. Manoj Krishna , K.V and Mamatha , H.V. (2010), Compaction and

[4] Strength behaviour of lime-coir fiber treated Black cotton soil Int. J of Geomechanicas and Engineering, 2, 19-28.

[5] Kumar, A., Balajit, S. W., and Mohan,J. (2006). "Compressive strength of fiber reinforced highly compressible clay." $J$ Construct. Building Mater. 20(10), 1063-1068.

[6] Shiv kumar Babu G.L, Vasudevan A.K, and Sayida M.K (2008). Use of coir fibers for improving the engineering properties of expansive soils. Journals of Natural Fibers, Vol.5 (1) $2008 p p$. 61-75.

[7] Prasad S.V, Pavithran.C, Rohatgi P. K. (1983). Alkali treatment of coir fibers for coir-polyester composites. Journals of Material Science 18. 1443-1445.

[8] Gray, D.H., Ohashi, H. (1983). Mechanics of fiber reinforcement in sand. Journal of Geotech. Eng. 109(3): 335353.

[9] Gray,D.H., Al-Refeai, T. (1986). Behaviour of fabric-versus fiber-reinforced sand. Journal of Geotech. Eng. 112(8): 804820.

[10] Freitag D.R (1986). Soil randomly reinforced with fibers. Journal of Geotech. Eng.112(8): 823-826 
[11] Callum A.S, Hill H.P.S, Abdul Khalil, Mike D, and Hale. (1997). A study of the potential of acetylation to improve the properties of plant fibers. Industial Crops and Psroducts 8. 5356.

[12] Nataraj,M.S and McManish, K.L. (1997). "Strength and deformation properties of soils reinforced with fibrillated fibers." J. Geosynth. Int., 4(1), 65-79.

[13] Mohanty A.K, Mishra .M, and Drzal L.T.(2001). Surface modifications of natural fibers and performance of the resulting bio-composites: An overview. Composite Interaces, Vol.8, No. 5, pp.313-343.

[14] Rout.J, Mishra.M, Tripathy.S.S, Nayak.S.K, and Mohanty. A.K(2001). The influence of fiber treatment on the the performance of coir-polyester composites. Composite Science and Technology 61(2001) 1303-1310.

[15] Bachitiar.D, Sapuan.S.M. And Hamdan.M.M. (2009). The influence of alkaline surface fibere treatment on the impact properties of sugar palm fiber-reinforced eposy composites.

[16] Hauang G.U (2009). Tensile behaviours of the coir fiber and related composites after $\mathrm{NaOH}$ treatment. Journals of Material and Design 30. 3931-3934.

[17] Prathap Kumar M.T and Jairaj. (2014). Shear Strength Parameters of BC Soil Admixed with Different Length of Coir Fiber. International Journal of Engineering Research \& Technology. Vol. 3 Issue 4, 1875-1878.

[18] Kelly C.C, Carvalho, Daniella R, Mulinari, Herman J.C, Voorwald, and Maria O.H. (2010). Chemical modification effect on the mechanical properties of hips/coconut fiber composites. Bio Resources 5(2), 1143-1155.

[19] Manoj Krishna K. V and Prathap Kumar M.T (2010). Water absorption and degradation behaviour of coir fiber under submerged condition. International conference- April 21-23, 2010

[20] Dutta R.K, Vishwas N.K, and Gyathir V. (2012). Effect of addition of treated coir fibres on the compression behaviour of clay. Journal of Civil Engineering (IEB), 40(2) 203-214.

[21] Rakesh Kumar, Sangeeta.O, and Aparan.S. (2011). Chemical modifications of natural fiber for compostie material. Der Chemical Sinica, 2011, 2 (4):219-228.

[22] Karthikeyan .A and Balamurugan K. (2012). Effect of alkali treatment and fiber length on impact behaviour of coir fiber reinforced epoxy composites. JSCI IND RES VOL.71pp.627631.

[23] Ramadevi P, Dhanlakshmi S, Chikkol V.S, and Basvaraju B. (2012). Effect of alkali treatment on water absorption of single cellulosic abaca fiber. Bio Resources 7(3), 3515-3524.

[24] Savita Dixit and Preeti Verma (2012). The effect of surface modification on the water absorption behaviour of coir fibers. Advances in Applied Science Research, 2012, 3 (3):1463-1465.

[25] Mizababaei .M, Miraftab .M, Mohamed.M, and McMahon.P. (2013). Unconfined compression strength of reinforced clays with carpet waste fibers. Journals of Geotechnical and Geoenvironmental engineering. 139:483-493.

[26] Channabasavaraju.W "understanding the engineering behavior of soil from an impact crater, India." (2015)issn:24544116,vol-1

[27] Channabasavaraju.W 'characterization of dredged sediments"(2014), by Indian Geotechnical Conference at JNTU Kakinada, Andra Pradesh, India.

[28] Channabasavaraju.W et. al. "Flood Control In Bangalore City For Sustainable Development: A Case Study", International Journal of Application or Innovation in Engineering \& Management Volume 6, Issue 7, July 2017.

[29] Suchit D. Gumaste el. Al. "Simulation of fabric in sedimented clays" Applied Clay Science 91-92 (2014) 117-126.

[30] Channabasavaraj and Dr. Ramalinga Reddy, "A review on characterization and application of fly ash zeolites", International Journal of Development Research, Vol. 07, Issue, 08, pp. 14294-14300, August, 2017.

[31] Manjularani.P et. al. "Augmenting the Properties of Black Cotton Soil Using Additives", International Journal of New Technology and Research (IJNTR) ISSN:2454-4116, Volume1, Issue-3, July 2015 Pages 42-45.

\section{ACKNOWLEDGEMENT}

The authors of this paper express their sincere thanks and gratitude to Channabasavaraj Wollur, Faculty, Department of Civil Engineering, Bharat Institute of Engineering and Technology, Hyderabad for helping in analysis of results and continues support through the conduction of experiments. 